\title{
Tuning Shims for High Field Quality in Superconducting Magnets*
}

\author{
R. Gupta, M. Anerella, J. Cozzolino, B. Erickson, A. Greene, A. Jain, \\ S. Kahn, E. Kelly, G. Morgan, P. Thompson, P. Wanderer, E. Willen \\ Brookhaven National Laboratory, Upton, NY 11973, USA
}

\begin{abstract}
A high field quality in interaction region quadrupoles is crucial to the luminosity performance of high energy colliders such as the Relativistic Heavy Ion Collider (RHIC). The field quality in magnets is limited in part by manufacturing tolerances in the parts and assembly. A tuning shim method has been developed to reduce the relative field errors $(\triangle B / B)$ from $-10^{-4}$ to $\sim 10^{-5}$ at $2 / 3$ of the coil radius. Eight tuning shims having $a$ variable thickness of iron are inserted after the construction and measurement of field harmonics in the magnet. In this paper the tuning shim technique is described for RHIC interaction region quadrupoles. The results of calculations and measurement are also presented.
\end{abstract}

\section{INTRODUCTION}

The Relativistic Heavy Ion Collider [1], [2] being built at Brookhaven National Laboratory (BNL) has six interaction regions. Each interaction region uses twelve $130 \mathrm{~mm}$ aperture quadrupoles [3] in four focusing triplets. In order to achieve a high luminosity, the beam will be squeezed to the smallest possible size $\left(\beta^{\circ}=1\right.$ meter $)$ in two interaction regions. An unavoidable consequence of this is a large increase in beam size in the interaction region quadrupoles. The aperture of these magnets should increase in proportion to the beam size to maintain the nominal field quality for the particle beam. This, however, is not practical for various reasons. As a result, the beam occupies a larger fraction of the aperture in these magnets. In RHIC, the ratio of beam size in these interaction region quadrupoles to the main ring $80 \mathrm{~mm}$ aperture quadrupoles is about seven whereas the ratio of coil apertures between the two is only about 1.6. Therefore, these quadrupoles strongly influence the beam life time during the high luminosity operation [4]. Moreover, a rapid change in beam size and phase advance within the interaction region focusing triplet limits the effectiveness of the correctors [4]. The tuning shim method described in this paper compensates for the field errors right at the source, i.e. in the aperture of these magnets. This compensation has a small current dependence due to iron saturation. The harmonics are minimized at $5 \mathrm{kA}(47.7 \mathrm{~T} / \mathrm{m})$ operation to maximize the luminosity at the top energy of the machine.

Manuscript received June 12, 1995.

c-mail address of the corresponding author : guptal@bnl.gov.

* This work is supported in part by the U.S. Department of Energy under contract No. DE-AC02-76CH00016.

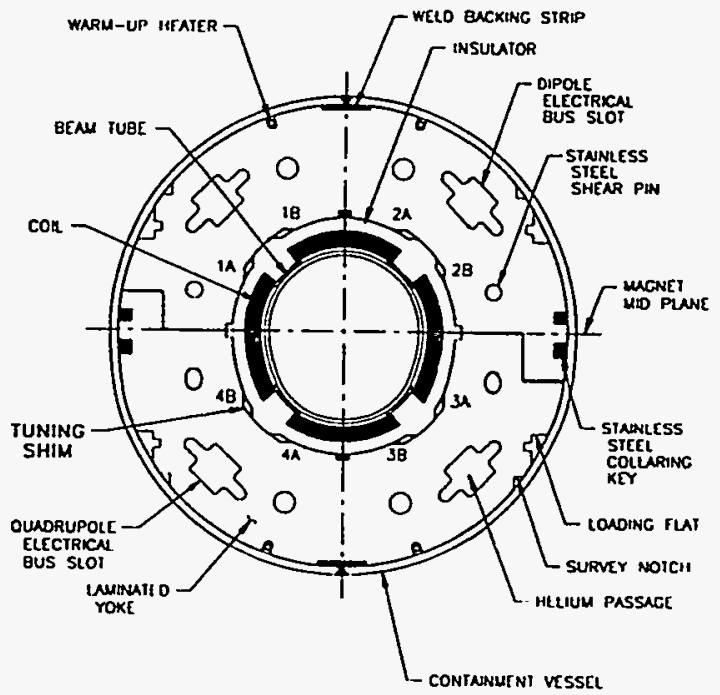

Fig. 1. Cross section of the $130 \mathrm{~mm}$ aperture RHIC interaction region quadrupoles. IA, IB, etc. are the locations of eight gaps for tuning shims.

\section{FIELD HARMONICS IN SUPERCONDUCTING MAGNETS}

The skew $\left(a_{n}\right)$ and normal $\left(b_{n}\right)$ components of field harmonics are defined as follows :

$$
B_{y}+i B_{x}=10^{-4} G \times R \sum_{n=0}^{\infty}\left[b_{n}+i a_{n}\right]\left[\frac{x+i y}{R}\right]^{n},
$$

where $B_{x}$ and $B_{y}$ are the components of the field at $(x, y), G$ is the gradient at the center of the quadrupole and $R$ is the reference radius, which is $40 \mathrm{~mm}$ in these magnets.

In a perfect quadrupole magnet, all harmonics except the fundamental one $\left(b_{1}=10^{4}\right)$ are zero. A non-zero value of the other harmonics may be due to (a) design deficiency from the limited number of parameters available in cross section optimization, (b) mechanical errors from the practical tolerances in the parts used in building magnets, and (c) errors or nonreproducibility in the manufacturing process. To get the harmonics better than a few units (or field errors better than $10^{-4}$ ), the cumulative deviation from the ideal geometry should be less than $0.05 \mathrm{~mm}$. This is at the limit of what can be practically achieved.

\section{MAGNET DESIGN}

The magnetic length of the three interaction region quadrupoles in the focusing triplet are $1.44 \mathrm{~m}, 3.4 \mathrm{~m}$ and $2.1 \mathrm{~m}$. They all have the same cross section. The detailed design of these magnets is described elsewhere [3].

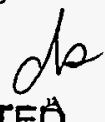


of field. The computed changes (as compared to the "no shim" or the "zero iron thickness" case) in skew $\left(a_{n}\right)$ and normal harmonics $\left(b_{n}\right)$ created by a 4 mm thick tuning shim at low current, are given in Table I. Whereas, the change in the magnitude and sign of allowed harmonics (transfer function, $b_{5}, b_{9}$, etc.), is independent of the shim location, the change in other harmonics depends on the location - at four locations the change has a positive sign and at the other four a negative sign. The computer code POISSON [6] is used for carrying out these calculations.

TABLE I

The Change in Harmonics due to a 4 ma Thick Tuning Shim (as Compared to the no Shim Case) at Varuous locations at low current. \&(TF) IS THE CHANGE IN TRANSFER FUNCTION IN T/m/kA.

\begin{tabular}{|c|c|c|c|c|c|c|c|c|c|c|c|}
\hline & $a_{0}$ & $a_{1}$ & $a_{2}$ & $a_{3}$ & $a_{4}$ & $a_{5}$ & $a_{8}$ & $a_{7}$ & $a_{8}$ & $a_{9}$ & 13 \\
\hline $\bar{A}$ & 1.83 & .37 & .72 & 3.49 & .62 & 1.30 & 0.41 & 0.01 & 0.09 & -0.08 & .001 \\
\hline$\overline{18}$ & 34 & & 79 & 88 & 47 & 30 & 60 & 011 & .16 & 08 & \\
\hline$\overline{2 A}$ & 34 & 36 & $\overline{79}$ & 49 & 17 & 30 & 60 & .01 & .16 & .08 & 10 \\
\hline$\overline{2 B}$ & .83 & 36 & 72 & 49 & .61 & .30 & .41 & .01 & .09 & .08 & \\
\hline$\overline{3 A}$ & 0.83 & $\overline{37}$ & $\overline{72}$ & 49 & 62 & 1.30 & $\overline{41}$ & 01 & .10 & .08 & $\overline{2 n}$ \\
\hline$\overline{3 B}$ & $\overline{34}$ & 37 & 80 & 49 & .47 & 1.30 & .60 & 01 & $\overline{16}$ & .08 & \\
\hline $4 A$ & 34 & 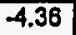 & 79 & 49 & 47 & 30 & .60 & .01 & 16 & .08 & \\
\hline שיד & 0.02 & , & 73 & 49 & 61 & 30 & 41 & .01 & .09 & .08 & \\
\hline \multirow[t]{2}{*}{$\overline{A L L}$} & 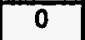 & 0 & 0 & $\overline{0}$ & $\overline{0}$ & 0 & 0 & 0 & $\overline{0}$ & 0 & 0 \\
\hline & $\mathbf{b}_{0}$ & $\delta(\mathrm{TF})$ & $b_{2}$ & $\mathbf{b}_{3}$ & $\infty$ & $\mathrm{D}_{5}$ & -6 & $\infty$ & 0 & $\rightarrow$ & 12 \\
\hline IA & -7.34 & .0104 & -7.80 & 3.30 & -0.47 & -0.55 & 0.60 & -0.37 & 0.16 & -0.04 & .004 \\
\hline 18 & $-10,82$ & .0104 & -1.72 & -3.30 & 2.61 & -0.55 & .41 & 0.37 & -0.09 & -0.04 & .004 \\
\hline $2 A$ & 10.82 & 104 & 1.72 & -3.30 & .61 & -0.55 & .41 & 0.37 & 0.09 & -0.04 & .004 \\
\hline $2 B$ & 7.34 & 104 & 7.80 & 3.30 & 0.48 & -0.55 & -0.60 & -0.37 & -0.16 & -0.04 & .004 \\
\hline $3 A$ & 7.34 & 3104 & 7.81 & 3.30 & 0.47 & -0.55 & -0.60 & -0.37 & -0.16 & -0.04 & .004 \\
\hline $3 \mathrm{~B}$ & 10.82 & 104 & 1.72 & -3.30 & -2.61 & -0.55 & 41 & 37 & .09 & -0.04 & .004 \\
\hline $4 \mathrm{~A}$ & 0.81 & 104 & .72 & -3.30 & 61 & -0.55 & .41 & 37 & -0.09 & -0.04 & $\overline{04}$ \\
\hline 48 & .35 & 104 & -7.80 & 3.30 & -0.47 & -0.55 & .60 & -0.37 & $\overline{0.16}$ & -0.04 & $\overline{04}$ \\
\hline & $\overline{0}$ & & 0 & & & 123 & & & & 35 & $.0 \Omega$ \\
\hline
\end{tabular}

\section{Calculations for High Fields Correction}

At high field the relative change in magnetization is not proportional to field and as a result the change in harmonics produced by tuning shims becomes current dependent. In Table II, we examine the loss in harmonic correction due to iron saturation. These calculations are performed for the harmonics created by the nominal size $(3.175 \mathrm{~mm})$ tuning shim. In Table II, the results of calculations are given for one of several shim locations that produced a maximum change in that particular harmonic. The calculations are performed for low current $(1 \mathrm{kA})$ and for the design current $(5 \mathrm{kA})$. The loss in correction due to iron saturation is typically less than $15 \%$, but in general it depends on the harmonic, and size and location of the shim.
TABLE II

The Change In Harmonics due to the Nominal SIzE SHIM (3.175 MM) AT LOW CURRENT (IKA) AND AT THE MAXIMUM DESIGN CURRENT (5 KA) AT ONE OF SEVERAL LOCATIONS THAT GIVES THE MAXIMUM CHANGE IN THAT HARMONIC. \&(TF) IS THE CHANGE IN TRANSFER FUNCTION IN T/M/KA.

\begin{tabular}{|c|c|c|c|c|c|c|c|c|c|c|}
\hline$I(k A)$ & $a_{0}$ & $a_{1}$ & $a_{2}$ & $a_{3}$ & $a_{4}$ & $a_{5}$ & $a_{6}$ & $a_{7}$ & $a_{8}$ & $a_{9}$ \\
\hline$L O C$ & $1 A$ & $1 B$ & $3 B$ & $1 B$ & $3 A$ & $1 A$ & $1 B$ & $1 B$ & $3 B$ & $1 B$ \\
\hline 1 & 7.87 & 3.31 & 5.67 & 2.43 & 1.87 & 0.86 & 0.41 & 0.27 & 0.12 & 0.06 \\
\hline 5 & 6.91 & 2.98 & 4.94 & 2.05 & 1.58 & 0.83 & 0.33 & 0.40 & 0.10 & 0.04 \\
\hline$I(K A)$ & $b_{0}$ & $\delta(T F)$ & $b_{2}$ & $b_{3}$ & $b_{4}$ & $b_{5}$ & $b_{6}$ & $b_{7}$ & $b_{8}$ & $b_{9}$ \\
\hline$L O C$ & $2 A$ & $A L L$ & $2 B$ & $1 A$ & $1 B$ & $A L L$ & $1 A$ & $1 B$ & $1 A$ & $A L L$ \\
\hline 1 & 7.87 & .0075 & 5.67 & 2.48 & 1.87 & -0.34 & 0.41 & 0.26 & 0.12 & -0.036 \\
\hline 5 & 6.91 & .0064 & 4.94 & 2.26 & 1.58 & -0.25 & 0.33 & 0.22 & 0.10 & -0.034 \\
\hline
\end{tabular}

\section{COMPARISON WITH MEASUREMENTS}

The validity of tuning shim method and model calculations has been investigated with a number of measurements. An exhaustive series of measurements have been done at room temperature (warm measurements) when a small current is carried by the copper in the cable. These measurements could be done much faster and although they do not reflect the true operating conditions, they nevertheless provide good verification for the harmonics created by a change in geometry. A limited number of measurements have also been performed (cold) at the design operating current ( $5 \mathrm{kA})$. In this section, a comparison between the calculations and measurements is presented.

\section{A. Warm Measurements}

During the warm measurements, we inserted tuning shims having thickness of $1.5875 \mathrm{~mm}, 3.175 \mathrm{~mm}$ (nominal) and $4.7625 \mathrm{~mm}$. The measurements were performed after inserting/changing a tuning shim in each of the eight locations to obtain the change from the "no shim" or "zero iron thickness" case. In Fig. 3, we show the measured change in harmonics for the given size tuning shim using 8 types of symbols for eight locations and the computed change by 8 types of lines. Good agreement between the calculations and measurements is apparent.

\section{B. Cold Measurements}

In Table III, we compare magnetic measurements at 5 $\mathrm{kA}$ with calculations when the thickness of the tuning shim in locations 1A, 2B, 3A, 4B was $2.91 \mathrm{~mm}$ and at other four locations was $3.44 \mathrm{~mm}$. This configuration creates only odd $b_{n}$ harmonics; others are not expected from symmetry. The measured values of such unexpected harmonics was within the measurement errors. A relatively large error in calculations is expected at $5 \mathrm{kA}$ due to the complexity of the computer model and uncertainty in the magnetic properties of the lamination stack used. 

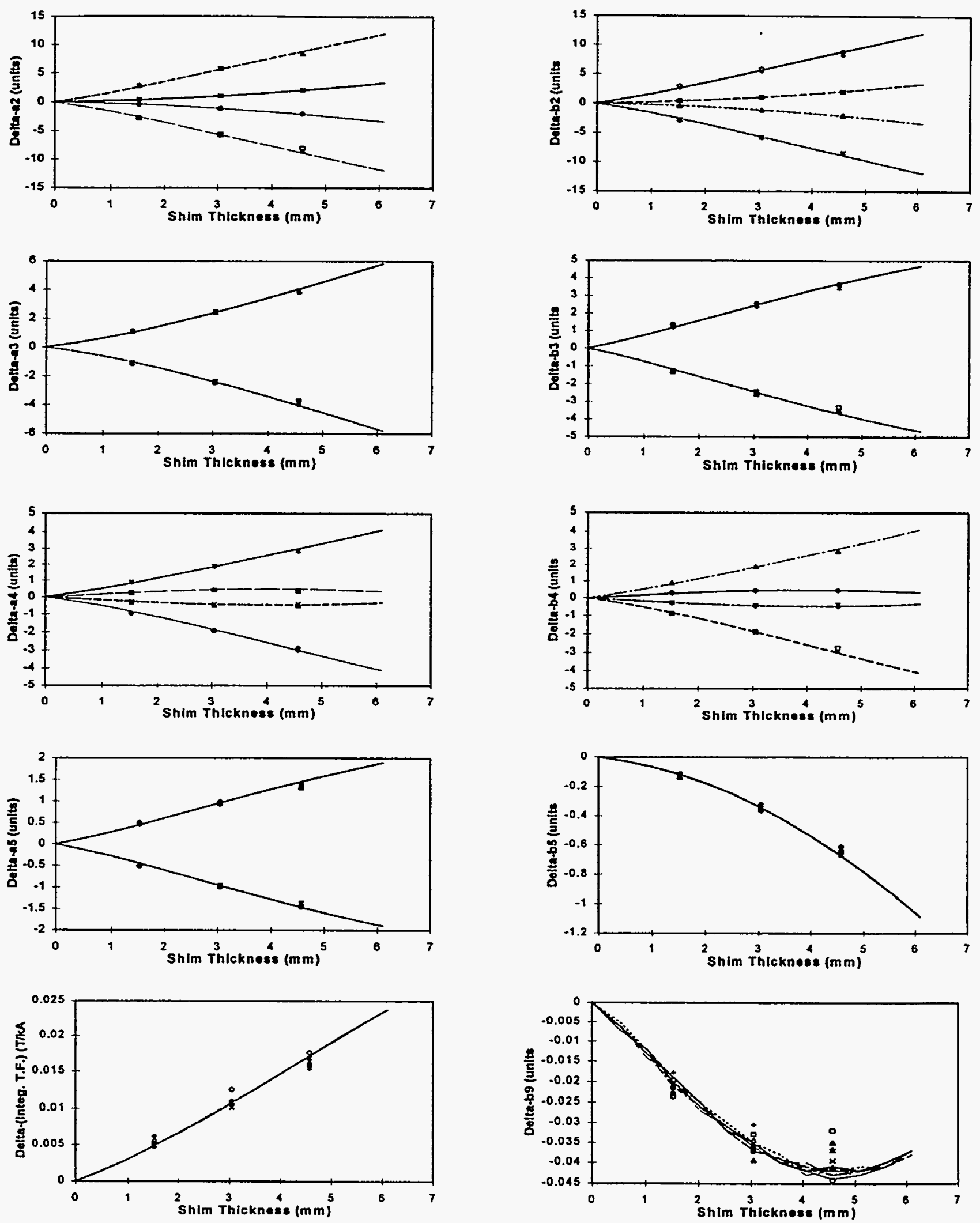

Fig. 3. A comparison between calculations and warm measurements for the field harmonics created by tuning shims. These are the changes in harmonics relative to the "no shim" or "zero iron thickness" case for each shim. The eight symbols represent the measurements for the eight tuning shim locations and eight lines are the calculations for these locations. 
TABLE III

The MeAsured aNd COMPUted Change IN haRMONICS AT 5 KA DUE to TUNING SHIMS HAVING A THICKNESS OF 2.91 MM AT LOCATIONS 1A, 2B, 3A, AND 4B AND 3.44 MM THICKNESS ELSEWHERE. $\delta(T F)$ IS THE CHANGE IN TRANSFER FUNCTION IN T/M/KA.

\begin{tabular}{|l|c|c|c|c|c|c|c|}
\hline & $\delta(T F)$ & $b_{3}$ & $b_{5}$ & $b_{7}$ & $b_{9}$ & $b_{11}$ & $b_{13}$ \\
\hline Computed & 0.052 & -1.3 & -2.0 & 0.15 & -0.27 & -0.01 & 0.02 \\
\hline Heasured & 0.050 & -0.8 & -1.7 & 0.12 & -0.27 & -0.01 & 0.02 \\
\hline
\end{tabular}

\section{PROCEDURE FOR HARMONIC CORRECTION WITH TUNING SHIMS IN RHIC INSERTION QUADRUPOLES}

The tuning shims will be installed inside the magnet without opening it. This makes the process more efficient since de-assembling and re-assembling of the magnet takes a long time and has a potential for damaging the magnet. Moreover, at the $10^{-5}$ level, the harmonics may change during reassembly, since the exact location of the conductors may not be reproducible during each magnet assembly.

The harmonic correction will be applied on the basis of warm measurements. This assumes that a good warm to cold correlation for the harmonics in the magnets and for the change produced by tuning shims is obtained prior to implementing this procedure. The thickness of eight tuning shims for each magnet would be computed to minimize the eight harmonics. The systematic values of field harmonics which are allowed by the magnet geometry, have been already minimized [7] so that a large tuning shim correction is not required. A second set of warm magnetic measurement will be performed to confirm the correct installation of the tuning shims. Finally, the harmonics will be measured cold at $5 \mathrm{kA}$, where they should be ideally zero. In principle, if the tuning shim correction is not satisfactory in this attempt, one can make a small iteration in tuning shim sizes to make the desired harmonics zero within the measurement errors.

\section{DISCUSSION}

A special situation arose in correcting the normal octupole $\left(b_{3}\right)$ harmonic in these magnets. This is a non-allowed harmonic in an ideal quadrupole geometry. However, for economic reasons, these quadrupoles are collared in a dipole press. The collaring process distorts the coil geometry such that a large $b_{3}(\sim 7$ units) is generated. If this is corrected by the tuning shim method alone, a large $b_{7}$ will be created. However, $b_{3}$ can also be corrected with an asymmetric coil to midplane gap between the horizontal and vertical planes [7]. This generates $a b_{7}$ that is of opposite sign to that generated in the tuning shim method. We have used a combination of the two methods to minimize both $b_{3}$ and $b_{7}$ harmonics.

The coil pole shims and coil midplane shims were adjusted during the magnet production to keep the values of allowed harmonics $b_{5}$ and $b_{9}$ low, so that a large tuning shim correction is not required.
A computer program SHIMCAL [8] has been written to compute the thickness of eight shims for compensating eight measured harmonics at $5 \mathrm{kA}$. At present it uses numerically computed coefficients based on POISSON calculations. Due to a large iron saturation at $5 \mathrm{kA}$ and due to complexity of the problem, analytic formulae can not be derived. Thus after a series of magnetic measurements at $5 \mathrm{kA}$, experimentally determined coefficients will be used in the program.

\section{CONCLUSIONS}

The field quality in superconducting magnets can be improved from the present $10^{-4}$ level to the $10^{-5}$ level using the tuning shim method described in this paper. Good agreement between the calculations and warm measurements as well as cold measurements proves the effectiveness of the concept. The use of the tuning shim method could also relieve the tolerances in parts and manufacturing of the magnets. However, a large correction in lower order harmonics could generate significant values of higher order harmonics.

\section{ACKNOWLEDGMENT}

M. Harrison's appreciation for the usefulness of the tuning shim method for the high luminosity collider was critical to the development of this program. Ongoing discussions with $\mathrm{S}$. Peggs and $\mathrm{J}$. Wei regarding the beam dynamics issues was the guide for improving field quality in the RHIC interaction region quadrupoles.

\section{REFERENCES}

[1] M. Harrison, "RHIC Status and Plans", Presented at the 1995 Particle Accelerator Conference, Dallas, Texas, May 1-5, 1995.

[2] A. Greene, et al., "The Magnet System of the Relativistic Heavy Ion Collider (RHIC)", this conference.

[3] R. Gupta, et al., "Large Aperture Quadrupoles for RHIC Interaction Region", Proceedings of the 1993 Particle Accelerator Conference, Washington, D.C., May 17-20, 1993, p 2745.

[4] J. Wei, R. Gupta, S. Peggs, "Magnetic Correction for RHIC Triplets", Proceedings of the 1993 Particle Accelerator Conference, Washington, D.C., May 17-20, 1993, p 258.

[5] K. Halbach, "Fields and First Order Perturbation Effects in Two Dimensional Conductor Dominated Magnets", Nucl. Inst. and Methods, 78, 1970.

[6] A. M. Winslow, "Numerical Solution of the Quasilinear POISSON Equation in a Nonuniform Triangular Mesh", J. of Comp. Phys., 2, pp. 149$172,1967$.

[7] R. Gupta, et al., "Field Quality Improvements in Superconducting Magnets for RHIC", Proceedings of the 1994 European Particle Accelerator Conference, London, UK, June 27 - July 1, 1994, p 2928.

[8] R. Gupta, "Iron Shims to Correct the Measured Harmonics in $130 \mathrm{~mm}$ Aperture RHIC Insertion Quadrupoles", Magnet Division Internal Note 480-16 (RHIC-MD-185), Dec 10, 1992, unpublished. 


\section{DISCLAIMER}

This report was prepared as an account of work sponsored by an agency of the United States Government. Neither the United States Government nor any agency thereof, nor any of their employees, makes any warranty, express or implied, or assumes any legal liability or responsibility for the accuracy, completeness, or usefulness of any information, apparatus, product, or process disclosed, or represents that its use would not infringe privately owned rights. Reference herein to any specific commercial product, process, or service by trade name, trademark, manufacturer, or otherwise does not necessarily constitute or imply its endorsement, recommendation, or favoring by the United States Government or any agency thereof. The views and opinions of authors expressed herein do not necessarily state or reflect those of the United States Government or any agency thereof. 